\title{
Avaliação de concretos de canais de drenagem urbana: estudo de caso
}

ANTÔNIO CARLOS ASSIS LEONEL - Mestrando em Construção CIIIL

Programa de pós-graduação em Geotecnia, Estruturas e Construção Civil - Universidade Federal de Goiás
TÚLIO PAIXÃo DE FRANÇA - DISCENTE de GRAdUaç̧̃o EM ENGENHARIA CIVIL Escola de Engenharia - Pontifícia Universidade Católica de Goiás

RODRIGO CARVALHO DA MATA - DiRetor ACADÉmico, Doutor

InStITUIÇÃo de ENSINo SUPERIOR de CACOAL - FANORTE

\section{RESUMO}

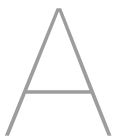

valia-se o concreto das paredes de contenção do canal do Córrego Botafogo por meio de inspeção visual, ensaio de determinação da profundidade de carbonatação e extração de testemunhos para ensaio de compressão e módulo de elasticidade, com a finalidade de fazer recomendações de monitoramento e manutenção para aumentar a vida útil da estrutura.

\section{INTRODUÇÃO}

Os canais destinados ao escoamento de águas superficiais e cursos d'água que permeiam o traçado urbano, tal como as obras de arte especiais, vêm sendo cada vez mais comuns nos grandes centros, haja vista a crescente expansão territorial dessas zonas urbanas.

Segundo Guabiroba (2012), nos canais urbanos é muito comum a utilização do concreto como material estrutural de contenção e revestimento. Assim sendo, a sua função, além de estrutural é assegurar a estanqueidade necessária para garantir a eficiência no trans- porte de água nas condições de escoamento projetadas. Apesar de constituir solução eficiente, essas estruturas precisam de uma atenção especial.

Embora o concreto seja o material de construção mais utilizado no planeta, seu desempenho está condicionado principalmente ao seu estado de conservação e, nessas estruturas, é comum o aparecimento de manifestações patológicas, em função da exposição a agentes agressivos presentes no meio em que estão inseridas, do seu uso contínuo e, em grande parte dos casos, da falta de programas preventivos de manutenção.

É importante ressaltar que muitas vezes os traçados dos canais urbanos são margeados por avenidas e vias que acabam por contribuir significativamente nas solicitações impostas às paredes do canal submetidas a carregamento dinâmico devido ao intenso tráfego. No Brasil têm-se como exemplos as Marginais Botafogo e Cascavel, em Goiânia-GO, Marginal Tietê, em São Paulo-SP e Avenida Marginal, em São Roque-SP. Outra situação bastante recorrente é que devido à excessiva impermeabilização do solo nas regiões circundantes ao canal, muitas vezes com alta densidade de edificações, o volume de água nos canais é intensificado em períodos de precipitação, podendo provocar inundações e até ruptura dessas estruturas. Nesse contexto, surge a proposta da avaliação do concreto das paredes de contenção do canal do Córrego Botafogo por métodos semidestrutivos e avaliar os resultados obtidos.

Os métodos semidestrutivos para investigação de estruturas de concreto acabadas visam a extração de amostras para posterior avaliação em laboratório. Embora essa extração apresente sinais de danificação no elemento estudado, não acarreta danos que possam comprometer a sua estabilidade e funcionalidade, desde que seguidas as devidas orientações normativas. Normalmente, essa metodologia é empregada quando se têm dúvidas acerca da resistência e desempenho do concreto lançado, seja por sinais de deterioração do material, causado principalmente 


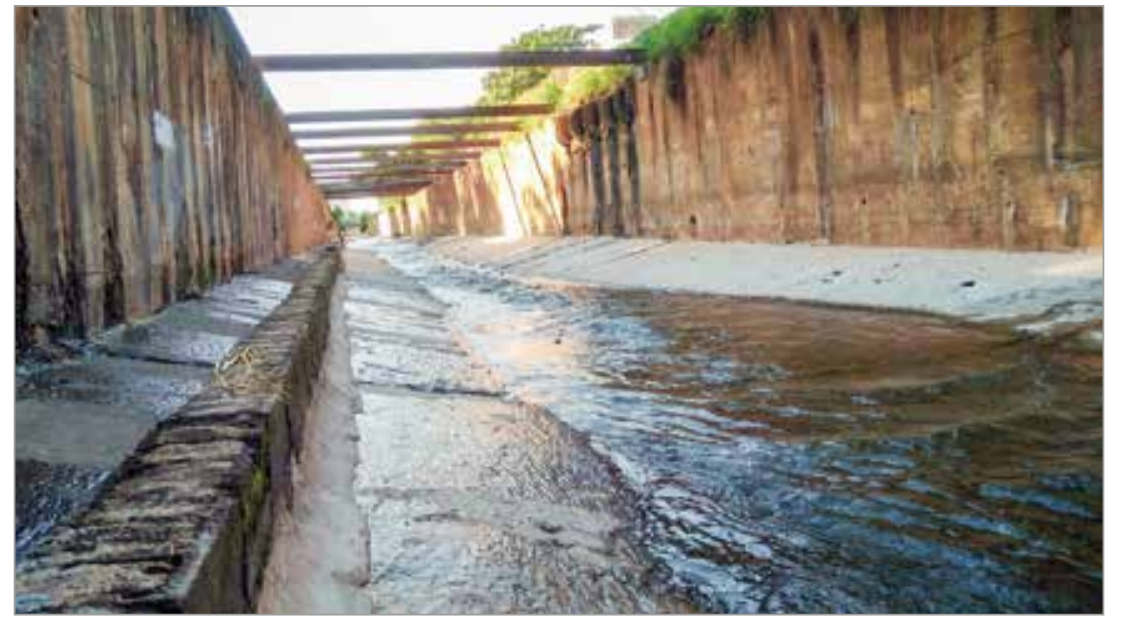

Fonte: Autores

Figura 1

Canal do Córrego Botafogo

pelos agentes agressivos do meio, seja por resultados de ensaios laboratoriais abaixo do esperado, durante o controle tecnológico.

\section{MATERIAIS E PROGRAMA EXPERIMENTAL}

O programa experimental consistiu na realização de ensaios semidestrutivos em dois locais, "A" e "B", da parede do canal do Córrego Botafogo (Figura 1), situado na região central de Goiânia, no período de outubro a novembro de 2018. Os locais definidos situavam-se

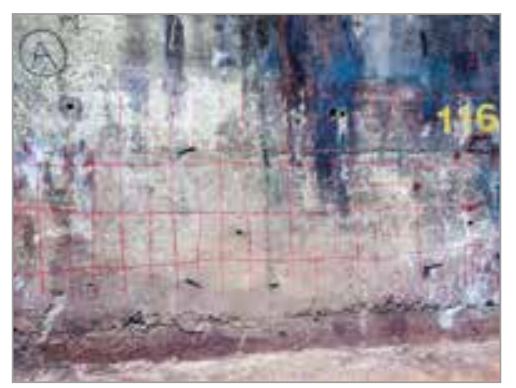

Fonte: Autores

Figura 2

Delimitação da região

de estudo - local "A" nas proximidades da obra de revitalização do fundo do canal, que estava sendo realizada, aproveitando, assim, toda a estrutura de canteiro e isolamento do perímetro presente no local.

A seleção dos locais exatos, referenciados em relação às estacas existentes da obra, foi realizada juntamente com os seus responsáveis técnicos e com os engenheiros fiscais da Secretaria Municipal de Infraestrutura e Serviços Públicos de Goiânia. O local "A" situava-se nas proximidades da estaca 09, referência 116, bordo oeste do canal (Figura 2). O local "B" situava-se nas proximidades da estaca 16, referência 109, também no bordo oeste do canal (Figura 3). Anterior à realização dos ensaios, fez-se a inspeção visual de toda a região de estudo, a fim de verificar a existência de manifestações patológicas na estrutura de contenção.

Em cada local, as análises foram realizadas em duas etapas: a primeira, de caráter de inspeção, que visou identificar a presença de manifestações patológicas e mapeamento de fissuras existentes; e a segunda, de caráter se- midestrutivo, que promoveu a extração de testemunhos de concreto, com a posterior análise de parâmetros de resistência e durabilidade do material, realizado no Laboratório de Inovação Tecnológica em Construção Civil LABITECC, da Universidade Federal de Goiás.

\section{I Inspeção}

Cada local de estudo compreendeu uma região de aproximadamente quatro metros de comprimento por três metros de altura ao longo do canal, para possibilitar a extração de todos testemunhos de concreto. Antes da realização dos ensaios, a parede teve de ser previamente limpa e lixada, a fim de retirar a poeira aderida à superfície do material.

Para o ensaio de pacometria, foi utilizado um scanner portátil com display digital, capaz de detectar a posição de armaduras e tubulações presentes no interior da parede do canal e, em seguida, realizou-se a sua marcação na superfície do concreto. Após a pacometria, realizou-se o mapeamento de fissuras existentes no local de estudo, bem como a medição de abertura dessas, com o auxílio de um

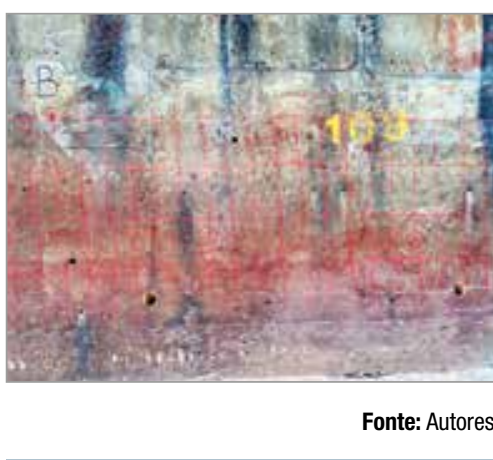

Figura 3

Delimitação da região de estudo - local "B" 
fissurômetro, com zoom óptico de 10x e resolução de 0,02 mm. As fissuras foram identificadas de forma numérica e sequencial.

\subsection{Ensaios semidestrutivos}

A realização dos ensaios semidestrutivos compreendeu basicamente a extração de testemunhos do concreto da parede do canal, realização da medição de profundidade de carbonatação in loco e realização de ensaios de compressão axial e módulo de elasticidade no laboratório LABITECC.

Para extração dos testemunhos de concreto, foi utilizada uma extratora perfuratriz, com broca de diâmetro de $100 \mathrm{~mm}$. Foram extraídos, em cada local, dez testemunhos de concreto com aproximadamente 100 mm de diâmetro e 200 mm de altura. Os testemunhos foram extraídos, preparados, cortados, armazenados e ensaiados seguindo os procedimentos estabelecidos na ABNT NBR 7680-1 (ABNT, 2015). Após extração, realizou-se a verificação da profundidade de carbonatação de todos os dez testemunhos, através da aspersão de solução de fenolftaleína,

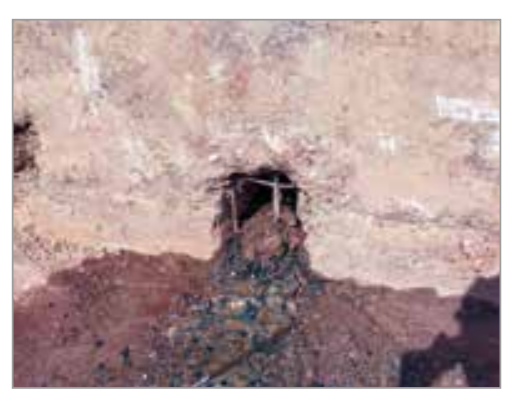

Fonte: Autores

Figura 4

Armaduras expostas na parede de concreto - local "A" conforme recomendação da RILEM CPC-18 (RILEM, 1988). As medições de profundidade de carbonatação foram realizadas com paquímetro digital com resolução de 0,01 mm. Em cada testemunho foram realizadas três medições de profundidade de carbonatação no sentido longitudinal.

Em laboratório, os testemunhos foram cortados, retificados e armazenados em tanque saturado com cal até a data de realização dos ensaios de compressão axial e módulo de elasticidade. As dimensões (diâmetro e comprimento) dos testemunhos foram feitas com uso de paquímetro digital com resolução de 0,01 mm.

Para realização do ensaio de compressão axial, seis testemunhos foram submetidos à ruptura de acordo com a prescrição da ABNT NBR 5739(ABNT, 2018), em prensa hidráulica classe I, com capacidade máxima de 2000 kN, sob velocidade de carregamento de 0,45 MPa/s.

Para realização do ensaio de módulo de elasticidade, foram utilizados três testemunhos, com as mesmas condições dos rompidos no ensaio de compressão axial. Adotou-se como valor de tensão de ruptura para o ensaio de módulo de elasticidade a média aritmética dos seis resultados corrigidos pelos coeficientes $\mathrm{k}_{1}$ a $\mathrm{k}_{4}$ obtidos no resultado de compressão axial. O ensaio foi realizado de acordo com a ABNT NBR 8522 (ABNT, 2017) e executado em prensa hidráulica classe I, com capacidade máxima de 300 kN, sob uma velocidade de carregamento de 0,45 MPa/s. Para aferição das deformações, utilizou-se de compressômetro com bases independentes, com dois relógios comparadores, com resolução de $0,001 \mathrm{~mm}$.

\section{RESULTADOS E DISCUSSÕES}

\section{I Inspeção visual}

A partir da inspeção visual realizada in loco, pôde-se verificar a existência de armaduras expostas em alguns pontos e presença de vegetação na junção de elementos estruturais, conforme ilustrado nas Figuras 4 e 5 .

Observou-se a possibilidade de existência de Reação Álcali-Agregado (RAA) nos testemunhos extraídos nos dois locais de estudo, através da presença de bordas bem demarcadas ao redor dos agregados, preenchimento dos poros com gel branco e microfissuração em alguns pontos, conforme ilustra a Figura 6. Segundo Hasparyk (2005), essas manifestações são as mais comuns verificadas em estruturas de concreto atacadas.

Embora detectada a possível existência de RAA, o fato de a estrutura não apresentar volumes significativos de concreto, uma vez que possui largura da seção transversal da ordem de $25 \mathrm{~cm}$ a $30 \mathrm{~cm}$, aplaca as preocupações existentes com essa reação. Entretanto, sugere-se

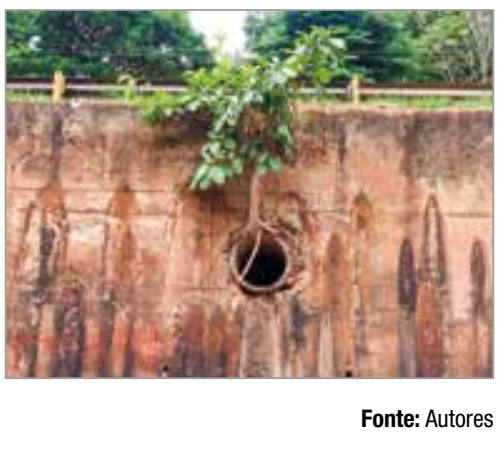

Figura 5

Presença de vegetação na parede do canal, entre estacas 15 e 16 

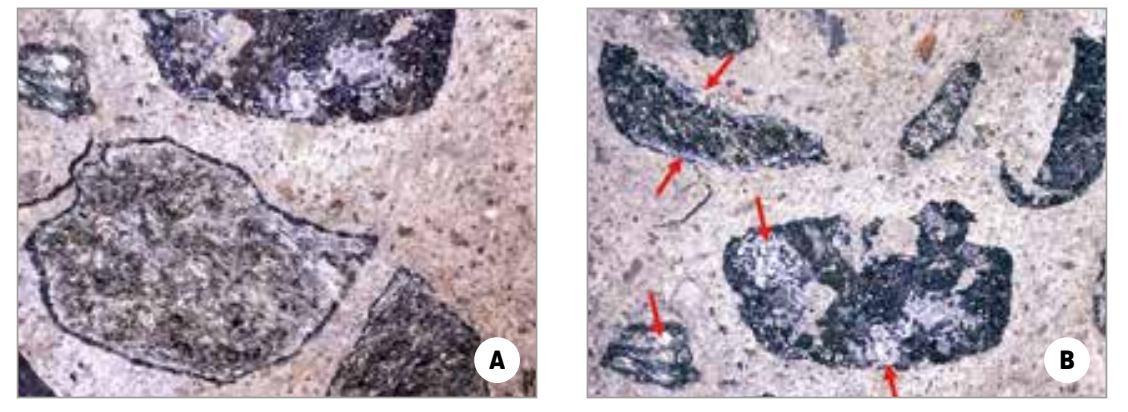

Fonte: Autores

Figura 6

Bordas bem demarcadas ao redor dos agregados (a) e formação de gel (b)

que seja feito um estudo mais aprofundado de RAA na estrutura para avaliar o nível de risco e de deterioração que ela poderá ocasionar.

As fissuras superficiais observadas, ilustradas na Figura 7, caracterizam-se por ser de origem congênita e dizem respeito aos efeitos da retração térmica e hidráulica do concreto, em sua fase de cura e endurecimento, não havendo relação com as solicitações mecânicas ou comportamentos estruturais anômalos.

$O$ registro das fissuras encontradas nas paredes de concreto do canal, nos dois locais de estudo, se apresenta na Tabela 1.

Do ponto de vista da durabili-
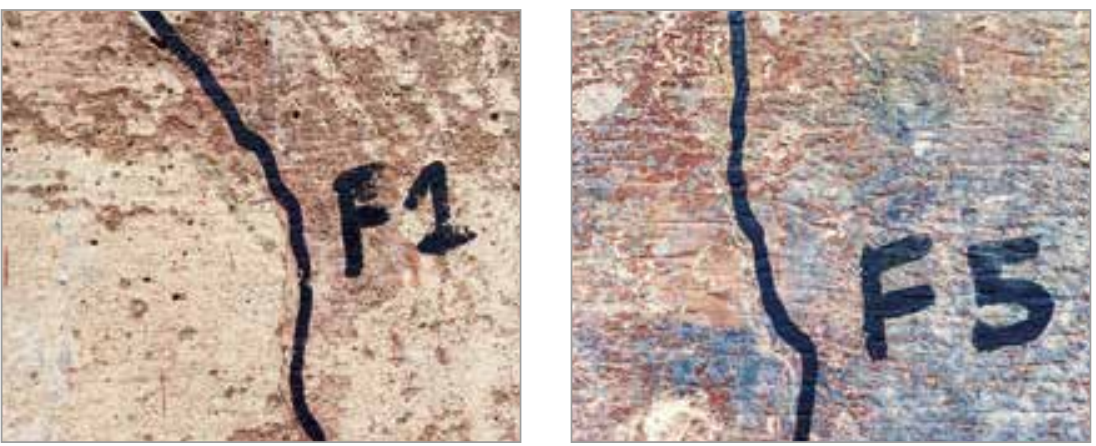

Fonte: Autores

Figura 7

Fissuras F1 e F5 observadas na parede do canal - local "A" estrutura de contenção.

\subsection{Profundidade de carbonatação}

Após a extração dos testemunhos, realizou-se in loco as determinações de profundidade de carbonatação do concreto através da leitura nos próprios testemunhos. Baseando-se no modelo proposto por Helene (1997), através da Equação 1, que promove a correlação entre o coeficiente de carbonatação e a resistência mecânica do concreto, foi estabelecido o cálculo dos coeficientes de carbonatação $\mathrm{K}_{\mathrm{CO} 2}$ em cada local de estudo. Fundametado nisso e a partir da Equação 2, proposta por Tuuti (1982), estimou-se a vida útil total da estrutura com base no cobrimento médio de $35 \mathrm{~mm}$ verificado in loco e a previsão de vida útil residual, considerando o tempo necessário para a completa carbonatação do cobrimento, ou seja, quando a frente de carbonatação atingiria a armadura. A Tabela 2 traz os valores obtidos a partir dessas determinações.

$k_{c o 2}=6,7882-0,1131_{f c k}$ podem estar sinalizando o início de uma provável ruptura de painéis da

\section{Tabela 1 - Abertura de fissuras} na parede do canal

\begin{tabular}{|c|c|c|}
\hline Local & Fissura & $\begin{array}{c}\text { Abertura } \\
\text { (mm) }\end{array}$ \\
\hline A & $\mathrm{F} 1$ & 0,12 \\
\hline$A$ & F2 & 0,10 \\
\hline A & F3 & 0,08 \\
\hline A & F4 & 0,16 \\
\hline A & F5 & 0,10 \\
\hline A & F6 & 0,02 \\
\hline$A$ & F7 & 0,10 \\
\hline$B$ & F1 & 0,14 \\
\hline B & $\mathrm{F} 2$ & 0,04 \\
\hline
\end{tabular}

Fonte: Autores 
\begin{tabular}{|l|l|}
\hline$e_{c o 2}=k_{c o 2} * \sqrt{t}$ & 2 \\
\hline
\end{tabular}

Dos resultados apresentados, pode-se concluir que, em média, o local "A" apresentou profundidade de carbonatação de $9,56 \mathrm{~mm}$ e o local “B”, 8,96 mm. Pode-se observar alta variabilidade da profundidade de carbonatação, o que revela heterogeneidade das características superficiais do concreto da estrutura. Logo, assume-se a possibilidade de existirem pontos com diferentes porosidades ao longo da mesma. Essa heterogeneidade pode ser atribuída a alterações na relação a/c entre as betonadas. Pode ser descartado a possibilidade de mau adensamento

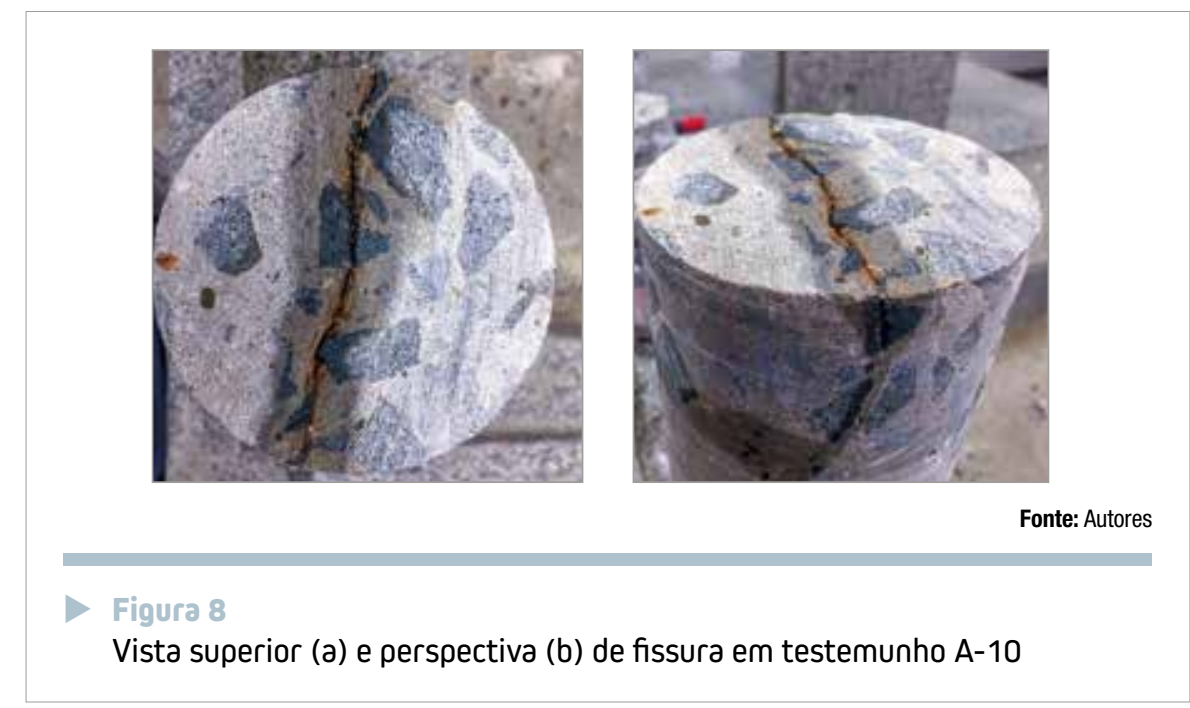

na concretagem, uma vez que não conclui-se que a previsão para a foram encontradas evidências de ninhos de concretagem ou sinais de mau adensamento. Também despassivação das armaduras, no local "A" para o caso mais desfavorável, ocorrerá em aproximadamente

\section{Tabela 2 - Estimativa de vida útil da estrutura}

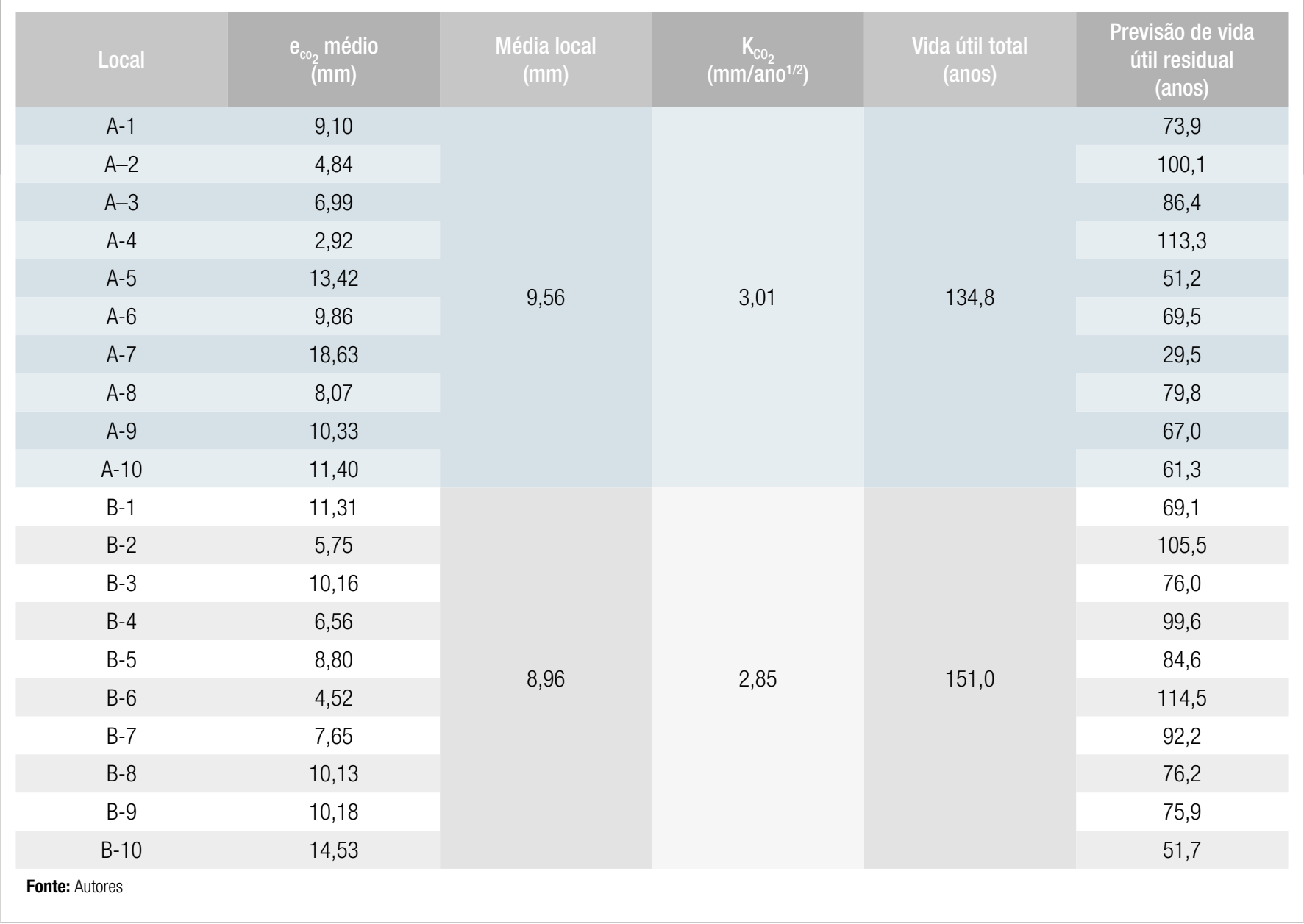


Tabela 3 - Resistência à compressão axial de testemunhos

\begin{tabular}{|c|c|c|c|c|c|}
\hline Testemunho & $\begin{array}{l}f_{c \text { ciext, inicial }} \\
(\mathrm{MPa})\end{array}$ & $\begin{array}{l}f_{\text {cilent }} \\
(\mathrm{MPa})\end{array}$ & $\begin{array}{l}f_{\text {ckkext,seg }} \\
(\mathrm{MPa})\end{array}$ & $\begin{array}{c}\text { Desvio padrão } \\
\text { (MPa) }\end{array}$ & $\begin{array}{l}\text { Coeficiente } \\
\text { de variação }\end{array}$ \\
\hline$A-1$ & 35,5 & 36,5 & \multirow{6}{*}{33,4} & \multirow{6}{*}{3,3} & \multirow{6}{*}{$9,79 \%$} \\
\hline$A-2$ & 29,8 & 32,6 & & & \\
\hline$A-5$ & 26,0 & 28,8 & & & \\
\hline A-6 & 37,2 & 36,1 & & & \\
\hline$A-8$ & 28,0 & 30,4 & & & \\
\hline A-9 & 34,0 & 35,8 & & & \\
\hline B-2 & 31,5 & 34,1 & \multirow{6}{*}{34,8} & \multirow{6}{*}{3,1} & \multirow{6}{*}{$8,77 \%$} \\
\hline B-4 & 33,9 & 36,9 & & & \\
\hline B-5 & 33,1 & 34,1 & & & \\
\hline B-7 & 33,8 & 36,9 & & & \\
\hline B-8 & 32,0 & 34,1 & & & \\
\hline B-10 & 26,3 & 36,9 & & & \\
\hline
\end{tabular}

29,5 anos. Já para o local "B", essa estimativa está para 51,7 anos.

\subsection{Resistência à compressão axial}

Os resultados obtidos a partir do ensaio de compressão axial dos testemunhos extraídos encontram-se na Tabela 3.

Os valores de $f_{\text {ci,ext,inicial }}$ referem-se aos resultados individuais obtidos diretamente do ensaio de compressão axial dos testemunhos extraídos. Após a correção desses valores pelos coeficientes $\mathrm{k}_{1}$ a $\mathrm{k}_{4}$, de acordo com a ABNT NBR 7680-1 (ABNT, 2015), têm-se os valores $f_{\text {ci,ext }}$. Esses coeficientes observados pela norma referem-se às características dimensionais do testemunho, o efeito de broqueamento em função do diâmetro, direção de extração em relação ao lançamento do concreto e o efeito da umidade no testemunho. O valor de $f_{c k, e x t, s e g}$ foi determinado a partir da média aritmética dos valores de $f_{c i, e x t}$.
Com base nos resultados apresentados, observa-se coeficientes de variação de 9,79\% para o local "A" e $8,77 \%$ para o local "B", nos valores corrigidos de resistência à compressão de testemunhos.

\subsection{Módulo de elasticidade}

Os resultados obtidos a partir do ensaio de módulo de elasticidade realizado nos testemunhos extraídos, de acordo com a ABNT NBR 8522 (ABNT,2017), encontram-se na Tabela 4.
Com base nos resultados apresentados, pode-se verificar um valor de módulo de elasticidade médio obtido para o local "A" 7,33\% menor que o local "B". Quando se analisa os valores juntamente com os desvios padrão obtidos, pode-se concluir que, mesmo com características constituintes distintas, observadas a partir da análise visual da proporção e tipologia de agregados graúdos e miúdos presentes nos testemunhos, os dois concretos possuem propriedades elásticas semelhantes.

Tabela 4 - Módulo de elasticidade estático de testemunhos

\begin{tabular}{|c|c|c|c|c|}
\hline Corpo de prova & $\begin{array}{c}\mathrm{E}_{\mathrm{oi}} \\
(\mathrm{GPa})\end{array}$ & Média & Desvio padrão & $\begin{array}{r}\text { Coeficiente } \\
\text { de variação }\end{array}$ \\
\hline A-5 & 38,1 & 34,9 & 2,75 & $7,88 \%$ \\
\hline A-7 & 32,8 & & & \\
\hline A-10 & 34,0 & & & $8,41 \%$ \\
\hline B-1 & 34,3 & 37,5 & 3,15 & \\
\hline B-6 & 37,6 & & & \\
\hline B-8 & 40,6 & & & \\
\hline Fonte: Autores & & & \\
\hline
\end{tabular}




\section{CONCLUSÕES}

Durante a inspeção visual realizada no canal, a presença de vegetação na junção de elementos estruturais, armaduras de aço expostas às intempéries e fissuras visíveis a olho nu denotam problemas nas ações de manutenção do canal, o que, a longo prazo, podem acabar comprometendo a durabilidade da estrutura e reduzindo a vida útil de projeto estabelecida. Além disso, após extração, através de análise visual, observou-se a possibilidade de reação álcali-agregado no material. Grande parte dos agregados apresentava contorno bem definido e preenchimento dos poros com material de cor branca, algo que é característico dessa manifestação patológica. Aparentemente, apesar de não evidenciar danos maiores às propriedades do concreto, recomenda-se estudo mais aprofundado quanto a esse fenômeno.

Analisando-se os dados obtidos na verificação da profundidade de carbonatação do material, observou-se que a carbonatação não tem afetado a estrutura de maneira severa. Tais valores, quando aplicados à estimativa de durabilidade restante da estrutura pelo método Tuuti (1982), denotam uma vida útil total da estrutura além dos 130 anos. É importante ressaltar que essa estimativa se baseia apenas na profundidade de carbonatação do concreto, não levando em conta a qualidade da manutenção do canal, a corrosão das armaduras, as variações hidrológicas ao longo das próximas décadas, a variação na taxa de $\mathrm{CO}_{2}$ na atmosfera, entre outros fatores.

Apesar da ausência de informações oficiais sobre as características do concreto, considera-se que a idade da construção dos locais estudados é de aproximadamente 40 anos. Tendo em vista que, nessa época, as construções apresentavam um menor uso de tecnologias de materiais e práticas de controle tecnológico aplicáveis ao concreto como existem hoje, os resultados se mostraram bastante favoráveis ao desempenho estrutural do canal, apresentando uma média de 34,1 MPa para a resistência à compressão axial e 36,2 GPa para o módulo de elasticidade estático, obtidos a partir dos testemunhos extraídos.

De uma maneira geral, pode-se concluir que os ensaios para determinação de parâmetros de resistência desenvolvidos nesse trabalho, quando analisados individualmente, apresentaram coeficientes de variação relativamente pequenos e em conformidade com o constatado na literatura. Com efeito, sugere-se ao poder público a execução de ações para minimizar problemas patológicos visualmente apontados, a fim de proporcionar uma maior amplitude da vida útil das paredes do canal estudado.

\section{AGRADECIMENTOS}

Os autores agradecem à Secretaria Municipal de Infraestrutura e Serviços Públicos da cidade de Goiânia, em especial ao Dolzonan da Cunha Mattos, Secretário de infraestrutura, e ao Antônio Henrique Capuzzo, Superintendente de Obras e Serviços Públicos, por terem apoiado a pesquisa e ter autorizado o acesso ao canal da Marginal Botafogo, assim como a JOFEGE Engenharia, pelo auxílio durante a realização dos ensaios, com maquinário e suporte de pessoal. Agradecem também ao laboratório LABITECC, em especial ao professor Daniel de Lima Araújo, coordenador geral, ao professor Oswaldo Cascudo, coordenador do laboratório de Durabilidade de Estruturas, e toda a equipe do laboratório e Escola de Engenharia Civil e Ambiental da UFG, por ter disponibilizado suas dependências, equipamentos e ferramentas necessárias à realização da pesquisa.

\section{> REFERÊNCIAS BIBLIOGRÁFICAS}

[01] ASSOCIAÇÃO BRASILEIRA DE NORMAS TÉCNICAS. ABNT NBR 5739: Concreto - Ensaios de compressão de corpos-de-prova cilíndricos. Rio de Janeiro: ABNT, 2018.

[02] ASSOCIAÇÃO BRASILEIRA DE NORMAS TÉCNICAS. ABNT NBR 6118: Projeto de estruturas de concreto - Procedimento. Rio de Janeiro: ABNT, 2014.

[03] ASSOCIAÇÃO BRASILEIRA DE NORMAS TÉCNICAS. ABNT NBR 7680-1: Concreto - Extração, preparo, ensaio e análise de testemunhos de estruturas de concreto - Parte 1: Resistência à compressão axial. Rio de Janeiro: ABNT, 2015.

[04] ASSOCIAÇÃO BRASILEIRA DE NORMAS TÉCNICAS. ABNT NBR 8522: Concreto - Determinação dos módulos estáticos de elasticidade e de deformação à compressão. Rio de Janeiro: ABNT, 2017.

[05] GUABIROBA, R. T. Patologias em canais de drenagem em concreto - Estudo de caso em BH. 2012. 62 f. Monografia (Especialização em Construção Civil) Departamento de Engenharia de Materiais de Construção, Escola de Engenharia da Universidade Federal de Minas gerais, Belo Horizonte, 2012.

[06] HASPARYK, N. P. Investigação de concretos afetados pela reação álcali-agregado e caracterização avançada do gel exsudado. 2005. 326f. Tese (Doutorado em Engenharia Civil) - Universidade Federal do Rio Grande do Sul, Porto Alegre, 2005.

[07] HELENE, P. R. L. Vida útil das estruturas de concreto. In: Congresso iberoamericano de patologia das construções, 4., 1997, Porto Alegre. Anais [...]. Porto Alegre, 1997. p. 1-30.

[08] RILEM CPC-18. Measurement of hardened concrete carbonation depth. Materials and Structures, 1988, p. 453-455.

[09] TUUTI, K. Corrosion of Steel in Concrete, Stokholm, 1982. 469 p. Swedish Cement and Concrete Research, p. 504. 